\title{
Gestão estratégica dos relacionamentos na cadeia de suprimentos da alface
}

\author{
Karine Lima de Carvalho ${ }^{\mathrm{a} *}$, Reinaldo Pacheco da Costa ${ }^{\mathrm{b}}$, Roberta de Castro Souza ${ }^{\mathrm{c}}$ \\ a*karine.carvalho@usp.br, EPUSP, Brasil \\ brpcosta@usp.br, EPUSP, Brasil \\ croberta.souza@usp.br, EPUSP, Brasil
}

\begin{abstract}
Resumo
Dentro da atual conjuntura delineada pelo deslocamento da fronteira tecnológica, notou-se a necessidade de reavaliar as formas organizacionais operantes na cadeia de suprimentos de produtos perecíveis, visando obter maior qualidade no produto através de uma melhor coordenação entre os agentes dessa cadeia. Sendo assim, este artigo se propõe a identificar os desafios a serem superados pelos produtores através do mapeamento dos seus gargalos por meio da análise das transações ao longo da cadeia de suprimentos de alface. A opção por este produto ocorreu em função da alta complexidade de gestão dessa cadeia, cuja produção pulverizada, com grande quantidade de produtores de perfis diferenciados, sofre com a dificuldade na elaboração de ações conjuntas que permitam o aprimoramento da sua gestão. Nesse contexto, as associações de produtores ganham importância e integram o processo estratégico que visa maior coordenação da cadeia.
\end{abstract}

Palavras-chave

Cadeia de suprimentos. Gestão. Coordenação. Alface.

\section{Introdução}

Para a teoria econômica tradicional, o comportamento dos agentes econômicos é analisado de maneira individualizada em que os pressupostos inerentes ao conhecimento pleno do mercado são simplificados pela óptica da função produção. Dentro desta estrutura de mercado, as decisões não são prejudicadas pelo número de concorrentes e, tampouco, pelos produtos homogêneos, dado o total acesso a variáveis que controlam o mercado. Entretanto, essa definição de mercado ressalta uma das principais críticas à abordagem, o fato de que nenhum setor econômico pode ser analisado de forma isolada, ou seja, sem considerar como e quais são as relações entre os agentes econômicos (SILVA; BATALHA, 1999).

Partindo dessa visão, o conceito de gestão da cadeia de suprimentos atualmente é tratado como ferramenta que permite ligar o mercado, o segmento de distribuição, o processo de produção, para simplificar o complexo processo entre as transações (COOPER; LAMBERT; PAGH, 1997; BOWERSOX; CLOSS, 2001; CHOPRA; MEINDL, 2009). Especialmente a cadeia de produtos perecíveis é alvo de constantes discussões
(WILSON, 1996; MANIKAS; TERRY, 2009; TAYLOR; FEARNE, 2009; PEREZ; CASTRO; FURNOLS, 2009; CLEMENTS; LAZO; MARTIN, 2008), pois cada vez mais a competição e as estratégias do varejo dependem de parceiros para garantir produtos de acordo com as exigências dos consumidores (WILSON, 1996; HUGHES; MERTON, 1996; FEARNE; HUGHES, 1999; DOLAN; HUMPREY, 2000; HINGLEY, 2001; CLEMENTS; LAZO; MARTIN, 2008).

Sendo assim, nesse início de século XXI, cresce entre os produtores o entendimento de que produzir não se limita à simples decisão de plantar e colher, é necessário atender aos desejos dos consumidores que, em geral, são influenciados pelo preço, pela qualidade e pela oferta diversificada de produtos. Assim sendo, e para que possam decidir o quê, como, quando e para quem produzir, os agricultores necessitam de suporte técnico adequado durante as fases de produção, pós-colheita e distribuição para assegurar que o consumidor final perceba o produto como sendo de qualidade (PÉNEAU et al., 2009). 
Diferentemente da cadeia de fornecimento do setor de alimentos do Reino Unido, que se destaca por ser uma das mais sofisticadas do mundo (HUGHES; MERTON, 1996; FEARNE; HUGHES, 1999; HINGLEY, 2001), a falta de garantia de suprimento regular de produtos de qualidade ainda é o principal problema da cadeia de suprimentos de frutas e legumes frescos no Brasil (FARINA, 1999; MACHADO, 2002). 0 setor de produtos hortifrutícolas, frutas e hortaliças frescas é, com raras exceções, o último segmento da produção vegetal a assimilar o avanço dos métodos e processos pós-colheita e se destaca por ser um dos menos desenvolvidos (MACHADO, 2002). Por isso, cada vez mais se torna estratégico compreender as inúmeras ligações entre os agentes econômicos com o objetivo de avaliar quais são as demandas dos clientes, quais características dos produtos frescos são priorizadas pelo mercado e como as funções de cada agente impactam no desempenho de toda a cadeia (DOLAN; HUMPREY, 2000; CLEMENTS; LAZO; MARTIN, 2008). Essas ações visam tornar a cadeia mais responsiva, capaz de suprir tanto as necessidades dos clientes quanto de lidar com situações inesperadas, como a sazonalidade e incerteza de demanda (CHOPRA; MEINDL, 2009). 0 resultado final, ou seja, o produto, reflete a soma dos valores adicionados por cada um dos elos ao longo da cadeia de suprimentos, resultando da coordenação entre os agentes (BESANKO; DRANOVE; SHANLEY, 2000).

Assim, visando contribuir com o conhecimento sobre a dinâmica dos relacionamentos na cadeia de suprimentos de produtos perecíveis, este trabalho se propõe a examinar como as transações ao longo da cadeia de suprimentos da alface ocorrem, especialmente pelo fato desse produto ser considerado o mais perecível dentre os que compõem a cesta hortícola. Com essa aplicação, pretende-se identificar e compreender os desafios a serem superados pelos agentes integrantes, sobretudo produtores.

0 artigo foi estruturado em cinco partes, incluindo essa introdução. A segunda parte trata da metodologia da pesquisa e, em seguida, é feita uma caracterização do setor. Na quarta seção são apresentados e analisados os resultados obtidos. Na quinta e última seção são expostas as considerações finais dos autores, as limitações da pesquisa e recomendações para trabalhos futuros.

\section{Objetivos da pesquisa}

Esta pesquisa tem como objetivo mapear e analisar as transações ao longo da cadeia de suprimentos da alface. A escolha desse objeto de análise decorre de essa hortaliça ser uma das mais consumidas de acordo com o Instituto Brasileiro de Geografia e
Estatística - Pesquisa de Orçamentos Familiares (INSTITUTO..., 2002-2003). Além disso, é considerado o produto hortícola mais perecível e com menor ciclo de vida - as perdas produtivas superam $40 \%$ do total, segundo a Companhia de Entrepostos e Armazéns Gerais de São Paulo (COMPANHIA..., 2007). Os problemas envolvem todos os elos, mas concentram-se principalmente no acondicionamento inadequado (19\%), na logística (17\%) e no manuseio (10\%).

Para tal objetivo, foi feita uma investigação para caracterizar, descrever e analisar como a cadeia de suprimentos da alface está estruturada. 0 intuito dessa etapa é identificar primeiramente os pontos fortes e os pontos fracos da cadeia e, subsequentemente, verificar como se dão as relações entre os elos e quais são as atividades desempenhadas por cada agente, para melhorar a coordenação da cadeia produtiva.

\section{Fundamentos teóricos}

Os estudos sobre agribusiness tiveram início com os trabalhos de Davis e Goldberg que, em 1957, publicaram A Concept of Agribusiness. Para esses autores, e posteriormente para Zylberstajn (1995), o aumento da conectividade facilitado entre os agentes e da colaboração mútua entre empresas através de redes de suprimento organizacionais reforça mais o conceito de que a competição se encontra no âmbito das cadeias de suprimento e não apenas entre empresas. Sendo assim, é fundamental priorizar o enfoque sistêmico da agricultura, enfatizando a importância de que todos os agentes e processos estejam interconectados.

Nessa visão sistêmica, abordam-se todas as ações, desde a produção dos insumos utilizados na agropecuária ao(s) elo(s) de distribuição e consumo, enfatizando a estreita dependência e as inúmeras relações da agricultura com os demais segmentos econômicos dentro da cadeia produtiva agrícola. E a competitividade está associada aos mecanismos de coordenação inter e intraorganizacionais.

Desde o trabalho desenvolvido por Davis e Goldenberg (1957), as questões relacionadas aos fornecedores e compradores foram e ainda são objeto de análise de diversas teorias subsequentes, tais como: Análise de Filière, Cadeia Produtiva, Sistema e Gestão da Cadeia de Suprimentos.

A gestão da cadeia de suprimentos tem representado uma nova e promissora fronteira para empresas interessadas na obtenção de vantagens competitivas. Inicialmente, o Gerenciamento da Cadeia de Suprimentos foi definido como uma

[...] metodologia desenvolvida para alinhar todas as atividades de produção de forma sincronizada 
visando reduzir custos, minimizar ciclos e maximizar o valor percebido pelo cliente final por meio do rompimento de barreiras entre departamentos e áreas [...] (WOOD JUNIOR; ZUFFO, 1998, p. 61).

Essa ferramenta, segundo Scramin e Batalha (2004), além de melhorar a competitividade, induz as empresas e os agente econômicos a operacionalizarem suas transações com maior eficiência, facilitando a constituição de parcerias. Por isso, para esses autores, a cadeia de suprimentos pode ser definida como o conjunto de etapas pelas quais os diversos insumos passam e vão sendo transferidos e transformados até constituírem o produto final. Nesse caso, o valor adicionado aos produtos é reflexo do desenvolvimento conjunto de competências e esforços distintos ao longo da cadeia de suprimentos.

No caso específico dos produtos perecíveis, a coordenação entre as etapas de produção e comercialização final (varejo) tem recebido atenção especial (HUGHES; MERTON, 1996), pois a crescente participação do varejo rompeu o ciclo básico dessas commodities transformando-as em culturas voltadas para a inovação (FEARNE; HUGHES, 1999; CLEMENTS; LAZO; MARTIN, 2008).

Dessa forma, um novo paradigma de negócio foi criado, sobretudo porque a competição perde seu caráter neoclássico, de firma, e passa a priorizar acordos com fornecedores para minimizar custos de distribuição, aumentar oportunidades e reduzir custos de transação (WILSON, 1996).

Entretanto, para que essas parcerias entre o varejo e seus fornecedores tenham sucesso, alguns critérios devem ser cuidadosamente priorizados e avaliados. 0 Quadro 1 indica quais são essas variáveis. Embora nem sempre as relações entre fornecedores e varejo sejam mutualistas (FEARNE; HUGHES, 1999), essa forte tendência na formalização de parcerias não são consideradas essenciais no processo de planejamento e coordenação (HINGLEY, 2001).

Como a maior dificuldade do varejo é monitorar as características dos produtos (incerteza de qualidade, fornecimento) e as necessidades dos clientes quanto ao produto perecível, sobretudo porque seu ciclo de comercialização é relativamente curto, as estratégias buscam coordenar a cadeia para garantir que o fluxo de informação seja disseminado entre todos os elos (CLEMENTS; LAZO; MARTIN, 2008).

Essa iniciativa de aproximação entre varejo e fornecedor é resultado também da ineficiência e inflexibilidade em termos de capacidade, utilização de espaço e fluxo de produtos dos centros de distribuição (MANIKAS; TERRY, 2009). Por isso, os autores concluem que cada vez mais o varejo tende a manter um número limitado de fornecedores. Fato esse comprovado pela pesquisa de Dolan e Humphrey (2000), que mostra um aumento progressivo no incentivo das redes varejistas ao desenvolvimento de suas cadeias de suprimentos através do monitoramento e controle dos fornecedores.

Por consequência, muitas cooperativas foram estruturadas para fazer a ligação do mercado com os produtores e, assim, minimizar as ineficiências decorrentes da falta de informação (BIJMAN; HENDRIKSE, 2003), pois a falta de colaboração, compartilhamento de informação e planejamento conjunto da produção primária são críticas ao gerenciamento de produtos frescos (TAYLOR; FEARNE, 2009).

\section{Metodologia}

A pesquisa abordará questões de natureza exploratória, de caráter qualitativo descritivo. Através da descrição dos acontecimentos e situações reais (VOSS; TSIKRIKTSIS; FROHLICH, 2002), pretende-se realizar uma generalização analítica dos fenômenos sociais para compreender o contexto dinâmico desses fenômenos (EISENHARDT, 1989). Neste caso, entende-se que o estudo de caso é o método, estratégia ou delineamento de pesquisa que melhor se adequa ao alcançar os objetivos propostos e à operacionalização de um trabalho com essas características (YIN, 1994).

0 objetivo principal do artigo é identificar as diversas formas de transação entre produtores e compradores (Ceagesp e supermercados). Para o levantamento das informações primárias foram realizadas entrevistas presenciais com os agentes integrantes da cadeia de suprimentos estudada e

Quadro 1. Critérios do varejo para formação de parcerias com fornecedores.

\begin{tabular}{|l|l|}
\hline \multicolumn{1}{|c|}{ Critérios } & \multicolumn{1}{c|}{ Pontos de avaliação } \\
\hline - Relacionamentos proativos & - Benefícios das parcerias \\
- Integração eletrônica completa & - O significado de relações formais \\
- Partilhar informação & - A importância da relação entre os pequenos e médios fornecedores \\
- Inovação de produtos, marketing ou gestão & - Poder e dependência da relação \\
- Investir em produtos e serviços específicos para o cliente & - Equilíbrio entre risco e recompensa \\
- Gestão da cadeia de suprimentos & - Exclusividade \\
\hline
\end{tabular}

Fonte: Adaptado de Fearne e Hughes (1999) e Hingley (2001). 
também coletadas informações oriundas de dados secundários. Ao todo foram estruturados quatro questionários, destinados a diferentes agentes, para facilitar o entendimento da dinâmica e o mapeamento da cadeia.

0 fato de o produto do estudo possuir características de fácil cultivo, não se dependendo de grandes extensões territoriais e grande dispêndio monetário para iniciar seu cultivo, foi crucial para atingir os objetivos deste estudo e delimitar as regiões a serem estudadas. Como a intenção da pesquisa não foi discutir com profundidade características de todas as regiões produtoras de alface, buscou-se primeiramente desenhar um cenário mais amplo, cujo foco é a produção de alface no estado de São Paulo. Posteriormente, restringiu-se a pesquisa de campo pelo volume comercializado em toneladas por cada município do estado de São Paulo na Ceagesp. A partir desses dados, Piedade e lbiúna se destacaram, dada a representatividade de ambos na comercialização ocorridas na Ceagesp e na produção da alface no estado (SÃO PAULO, 2008). Portanto, foram definidos como referência para análise e mapeamento da cadeia de suprimentos de alface. Além disso, através dos dados obtidos na Ceagesp foi possível identificar os atacadistas da Ceagesp que se destacam por município. Dentre os permissionários, nove foram entrevistados; adicionalmente, também foram conduzidas entrevistas com o responsável pelo Centro de Qualidade em Horticultura (SECCQH).

Optou-se por também entrevistar os produtores desses municípios, buscando-se complementar as informações sobre as relações existentes na cadeia estudada. Houve a preocupação de heterogeneizar a amostra de produtores entrevistados para viabilizar a compreensão das diferenças existentes nesses processos entre os diversos nichos de produtores (grandes, médios e pequenos).

Já o critério para escolha dos agentes varejistas (supermercados) a serem entrevistados foi embasado na atual conjuntura do mercado. A constante busca pela modernização motivou o setor varejista a aperfeiçoar funções ligadas ao abastecimento das lojas para diminuir a intermediação comercial (HUGHES; MERTON, 1996; FEARNE; HUGHES, 1999; HINGLEY, 2001; DOLAN; HUMPREY, 2000; CLEMENTS; LAZO; MARTIN, 2008). Além disso, sempre houve no Brasil a preponderância da comercialização desses produtos em feiras livres. Somente nos últimos dez anos começou a se observar a queda da participação das feiras em razão do aumento de interesse dos supermercados na comercialização de produtos frescos (REARDON; HENSON; BERDEGUE, 2007). Portanto, optou-se, para este estudo, incluir somente as transações envolvendo os supermercados. A definição de quem seriam os entrevistados foi embasada no ranking 2007 da Associação Brasileira de Supermercados (ASSOCIAÇÃO..., 2007), que anualmente divulga os maiores varejistas de alimentos no país. Para essa classificação, buscou-se entrevistar varejistas de grande e médio porte, incluindo um dos maiores varejistas do país. Ao todo, foram realizadas três entrevistas com agentes do segmento.

Por fim, foi realizada uma entrevista com uma associação de produtores denominada Associação dos Produtores e Distribuidores de Horti-Fruti do Estado de São Paulo (Aphortesp). As entrevistas foram realizadas com produtores associados, engenheiros agrônomos do Sindicato Rural de Mogi das Cruzes, Consultor da Aphortesp. Essa etapa teve como objetivo compreender os benefícios reais de ser um produtor associado. Bijman e Hendrikse (2003) mostram que o objetivo dessas associações é ampliar a carteira de produtos e serviços que complementam as atividades dos produtores. Nesse sentido, o objetivo dessa etapa foi entender o funcionamento dessa associação de produtores de hortifrúti e as vantagens e desvantagens de ser um produtor associado.

\section{Panorama do setor: produção de alface no estado de São Paulo}

Nos últimos anos tem-se registrado um amplo movimento de reestruturação do agronegócio mundial, impulsionado principalmente pelos avanços tecnológicos nas diferentes áreas do conhecimento. 0 poder de persuasão social das comunicações afetou o comportamento dos consumidores, induzindo-os a mudanças nos hábitos alimentares (DOLAN; HUMPREY, 2000) e gerando maior consumo de determinados produtos.

Entretanto, dados da Pesquisa de Orçamentos Familiares (2002/2003) revelam que no Brasil o gasto das famílias com alimentos supérfluos ainda é $110 \%$ maior que as despesas com frutas, legumes e verduras (FLV). 0 consumo por dia desses alimentos ainda é baixo, $150 \mathrm{~g} /$ pessoa em relação ao consumo recomendado $500 \mathrm{~g} /$ pessoa (BOTEON, 2006). Mainville e Peterson (2005) ilustram que o consumo per capita de FLV no Brasil está em torno de $40 \mathrm{~kg} / \mathrm{ano}$, contrapondo o consumo per capita dos Estados Unidos, que alcança patamares próximos a $143 \mathrm{~kg} / \mathrm{ano}$.

Mesmo com patamares de consumo abaixo da expectativa quando comparados aos de outros países, do ponto de vista macroeconômico o setor de hortaliças no Brasil é responsável por uma das mais altas relações de empregos gerados por hectare quando comparado a culturas extensivas como cereais (ROCHA, 2007). Contudo, por ser uma cadeia 
composta de produtos altamente perecíveis, a falta de coordenação contribui para acentuar as perdas, o que evidencia ainda mais a necessidade de tornar os processos mais eficientes e permitir a oferta de produtos com melhor qualidade e preços acessíveis ao consumidor.

Especificamente, a produção por ano da alface está presente em todas as regiões, porém São Paulo (164.774 t), Rio de Janeiro (143.370 t) e Minas Gerais (36.011 t) se destacam (EMBRAPA, 2010). 0 estado de São Paulo é a região brasileira com a maior concentração de produtores de alface e, consequentemente, o maior produtor de hortaliças. Quase $48 \%$ da produção total (SÃO PAULO, 2008) destinada exclusivamente ao consumo interno é proveniente de Unidades de Produção Agrícola - UPAs - localizadas nos municípios de lbiúna (14,07\%), Mogi das Cruzes (6,99\%), Suzano $(5,92 \%)$, Piedade $(5,90)$, Biritiba-Mirim $(5,02 \%)$, Salesópolis (2,77\%), São Paulo (2,19\%), Campinas $(1,84 \%)$, Ribeirão Preto $(1,67 \%)$ e Cotia $(1,40 \%)$

Em todo o estado de São Paulo existem 324.601 pequenas e médias UPAs. Dessas, 3.546 se dedicam ao cultivo de alface, sendo que 54\% possuem extensão fundiária menor que 20 alqueires (SÃO PAULO, 2008). Embora quase $71 \%$ dessas UPAs estejam filiadas a algum tipo de instituição, isto é, associações, sindicatos ou cooperativas, somente 29,91\% recorrem a assistência técnica privada durante o cultivo (SÃO PAULO, 2008). A Tabela 1 evidencia alguns dos motivos que tornam a cadeia de produtos frescos, em especial a alface, tão precária no Brasil. Esses indicadores mostram que algumas UPAs são capazes de agregar valor ao produto com o propósito de melhorar a qualidade percebida pelo comprador. Em contrapartida, a grande maioria negligencia a utilização de métodos e técnicas que agregam valor ao produto, como seguridade do alimento, rastreabilidade dos insumos utilizados, melhoramento do manuseio e plantio etc.

Portanto, a classificação, o uso de embalagens adequadas e de rótulos com perfeita identificação do produto podem evitar perdas, pois a alface é uma das hortaliças mais perecíveis, além de não tolerar congelamento (COMPANHIA..., 2007). Embora essa cadeia de suprimentos seja composta por produtos em sua maioria de baixo custo unitário, o setor já está sofrendo modificações em sua estrutura em virtude das exigências da nova demanda. No passado, os agentes que compunham toda a cadeia de suprimentos não priorizavam a qualidade de insumos e a eficiência no acondicionamento para evitar perdas no transporte. Agora a questão é em torno da garantia da qualidade, e a coordenação eficiente de todos os processos que integram a cadeia é crucial para atingir objetivos estratégicos e competitivos dentro desse novo ambiente mercadológico. Sendo assim, a diversificação se tornou uma das alternativas para os sistemas produtivos continuarem crescendo (PENROSE, 1959).

Outro ponto é em relação à forma de comercialização. A princípio a comercialização de hortaliças pelos supermercados era vista apenas como uma forma de atrair o consumidor. Porém, com o crescimento das vendas de perecíveis, a representatividade do setor aumentou em relação ao faturamento total do varejo entre $8 \%$ e $12 \%$ (PEDROZO, 2007) e esse passou a ser estratégico

Tabela 1. Indicadores socioeconômicos, estado de São Paulo (2007-2008).

\begin{tabular}{lcc}
\hline \multicolumn{1}{c}{ Item } & Número de UPAs & Percentual \\
\hline Utiliza assistência técnica governamental & 155.902 & 48,03 \\
Utiliza assistência técnica privada & 97.099 & 29,91 \\
Utiliza crédito rural & 49.917 & 15,38 \\
Utiliza seguro rural & 10.926 & 3,37 \\
Utiliza escrituração agrícola & 92.997 & 28,65 \\
Acessa internet p/ fins da agropecuária & 19.361 & 5,96 \\
Utiliza computador nas atividades agropecuárias & 20.610 & 6,35 \\
Utiliza energia elétrica na atividade agrícola & 248.006 & 76,40 \\
Realiza análise de solo, quando necessário & 104.691 & 32,25 \\
Utiliza práticas de conservação de solo, quando necessário & 179.439 & 55,28 \\
Faz adubação mineral, quando necessário & 169.504 & 52,22 \\
Faz adubação orgânica, quando necessário & 85.462 & 26,33 \\
Faz adubação verde, quando necessário & 20.428 & 6,29 \\
Utiliza manejo integrado de pragas (MIP) & 8.804 & 2,71 \\
Utiliza hidroponia & 348 & 0,11 \\
Utiliza plasticultura & 5.427 & 1,67 \\
Utiliza mudas fiscalizadas & 58.020 & 17,87 \\
Utiliza semente melhorada & 82.378 & 25,38 \\
\hline
\end{tabular}

Fonte: São Paulo, (2008). 
(Quadro 2). Com essa crescente participação das grandes redes supermercadistas, os produtos passaram a ser comercializados de forma mais eficiente e esses agentes criaram padrões de qualidade próprios. Fatos confirmados por parcerias estratégias entre algumas redes varejistas em países desenvolvidos que conseguiram reduzir custos e garantir qualidade e quantidade (REARDON; HENSON; BERDEGUE, 2007). Em função disso, as relações comerciais entre os agentes da cadeia de suprimentos estão se modificando e a habilidade de desenvolver e administrar com sucesso seus relacionamentos tornou-se uma competência essencial (PIGATTO; ALCANTARA, 2007).

As estratégias dos varejistas com os diferentes agentes da cadeia de suprimentos da alface podem variar bastante em função do tamanho da rede varejistas (pequena, média ou grande), sendo possivel classificá-las de acordo com o grau de sofisticação do relacionamento, conforme exposto no quadro 2 . De maneira geral, as grandes redes procuram atuar de forma mais próxima de seus fornecedores, visando a melhor coordenação da cadeia de suprimentos, por meio de treinamentos, obtenção de certificação de qualidade etc. (VASCONCELOS; MILAGRES; NASCIMENTO, 2005).
Entretanto, os supermercados de pequeno porte, em geral, não possuem capacidade técnicofinanceira para efetuar ajustes. Ademais, por não terem escala operacional compatível à das grandes redes varejistas, nem mesmo poder de barganha, enfrentam dificuldades junto aos fornecedores para conseguir preços competitivos.

\section{A pesquisa de campo: características da cadeia de suprimentos da alface}

A análise e caracterização de todos os agentes envolvidos na distribuição e comercialização da alface possibilitaram identificar os integrantes da cadeia de suprimentos nas regiões estudadas. A Figura 1 fornece uma visão simplificada da cadeia de suprimentos de alface.

No primeiro nível da cadeia ocorre a primeira transação entre os fornecedores de insumo e o produtor. Os produtores entrevistados não buscam compartilhar informações com outros membros e parceiros comerciais, sobretudo para conseguir melhores preços. Nessa etapa, o fornecedor de insumo é quem informa as tendências de mercado e técnicas de plantio. Por isso, o risco de assimetria

Quadro 2. Estratégia de relacionamento dos supermercados na cadeia de suprimentos.

\begin{tabular}{|c|c|c|}
\hline \multicolumn{3}{|c|}{ Estratégia atual de relacionamento } \\
\hline Agente & Menos sofisticada & Mais sofisticada \\
\hline Fornecedor & $\begin{array}{l}\text { 1. Obter os melhores preços, qualidade e condições de } \\
\text { fornecimento. } \\
\text { 2. Estabelecer maior comunicação com os fornecedores, } \\
\text { para facilitar o fluxo de informação e consequentemente } \\
\text { reduzir perdas. }\end{array}$ & $\begin{array}{l}\text { 3. Desenvolver relações mais próximas com fornecedores, visando } \\
\text { a melhoria geral da cadeia produtiva. } \\
\text { 4. Preocupação em incluir o segundo nível de fornecedores } \\
\text { (fornecedores parceiros). }\end{array}$ \\
\hline Distribuidor & $\begin{array}{l}\text { 1. Obter as melhores margens e condições de pagamento. } \\
\text { 2. Estabelecer maior colaboração e comunicação com os } \\
\text { distribuidores, para facilitar as transações. }\end{array}$ & $\begin{array}{l}\text { 3. Desenvolver ações cooperativas com os distribuidores, visando } \\
\text { produzir maior valor em conjunto. }\end{array}$ \\
\hline $\begin{array}{l}\text { Consumidor } \\
\text { final }\end{array}$ & $\begin{array}{l}\text { 1. A empresa percebe a importância do consumidor final, } \\
\text { mas não o inclui nas suas estratégias. } \\
\text { 2. Comunicação indireta com os consumidores finais por } \\
\text { meio de seus distribuidores e/ou clientes. }\end{array}$ & $\begin{array}{l}\text { 3. A empresa mantém um canal aberto de comunicação com seus } \\
\text { consumidores finais, visando conhecer suas necessidades. } \\
\text { 4. A empresa mantém um canal aberto de comunicação com seus } \\
\text { consumidores e inclui este conhecimento na formulação de sua } \\
\text { estratégia. }\end{array}$ \\
\hline
\end{tabular}

Fonte: Adaptado de Vasconcelos, Milagres e Nascimento (2005).

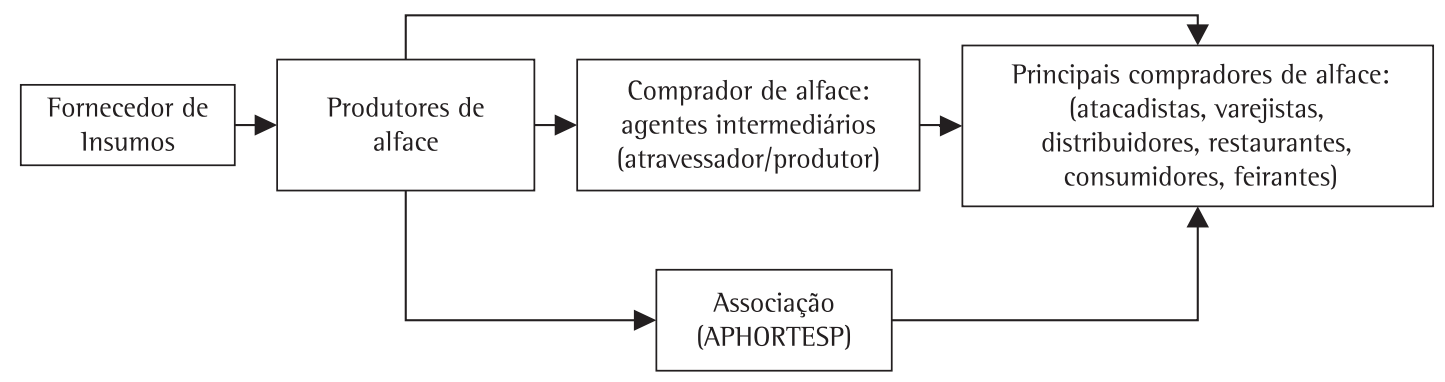

Figura 1. Modelo genérico do fluxo das transações ao longo da cadeia de suprimentos. 
informacional é alto, pois dependem da confiança mútua, resultante do relacionamento de vários anos.

0 segundo nível consiste na produção de alface. Pode-se considerar no mesmo estágio também o nível representado pelas ações coletivas, que para este trabalho estão representadas pela Aphortesp. As atividades de colheita e transporte são comuns para ambos. No entanto, para os produtores associados, como há vários parceiros envolvidos, os produtos são levados pelos parceiros até as packing-houses para seleção, lavagem, higienização e empacotamento da alface. Embora as etapas envolvendo produção, colheita e transporte acarretem grandes perdas, causadas por excesso de manuseio, o produto beneficiado tem sua vida útil prolongada, o que evita perdas maiores durante a comercialização.

0 terceiro nível envolve as transações entre produtores e compradores, que podem ser outros produtores, atacadistas e varejistas. Resumidamente, o produtor se defronta com diferentes níveis de atacado e varejo. Para ambos, a confiança mútua coordena as atividades. Como ressaltado por Manikas e Terry (2009), nesse ponto, os problemas em relação aos centros de distribuição de produtos frescos no Reino Unido são muito próximos do que ocorre no Brasil, pois apesar de possuir um dos canais de distribuição mais sofisticados do mundo (FEARNE; HUGHES, 1999; HINGLEY, 2001), os varejistas optam por manter um número limitado de centros de distribuição como fornecedor. Tal semelhança é devida principalmente à natureza e magnitude de problemas logísticos como: ineficiência na utilização de câmaras frias para armazenamento e ineficiência de tempo e processo em relação às tarefas de controle de qualidade que dificultam o fluxo de produto (MANIKAS; TERRY, 2009).

A Ceagesp não possui câmaras frias para acondicionamento do produto e uma minoria de permissionários possui transporte com essas características. Por isso, os centros de distribuição de uma forma geral são classificados como ineficientes e inflexíveis em termos de capacidade e fluxo de produto. Dessa forma, cada vez mais os varejistas tendem a reduzir ou excluir fornecedores que comercializam nesses locais. Os supermercados evitam transações com intermediários (atacadistas) e optam pela compra direta do produtor. Esses relacionamentos são geralmente duradouras e o comprador tem um maior controle sobre informações referentes à qualidade e à quantidade do produto. Esse resultado corrobora com o das pesquisas de Wilson (1996), Hughes e Merton (1996), Fearne e Hughes (1999), Dolan e Humprey (2000), Hingley (2001) e Clements Lazo e Martin (2008), sendo que em alguns casos há predominância de contratos formais de fornecimento.
Além disso, o número de fornecedores do varejo é restrito, para que não se perca o controle sobre produto e produtor.

A Aphortesp é uma associação que tem como objetivo representar seus associados promovendo a difusão de conhecimentos científicos e tecnológicos em uma das maiores e mais complexas cadeias produtivas de agronegócio do estado de São Paulo. Dentre os membros, há mais de 700 produtores parceiros, com uma área total de produção de aproximadamente 1.200 ha e produção diária de aproximadamente 350 mil pés de hortaliças distribuídos entre propriedades próprias, arrendadas e de parceiros/fornecedores, gerando aproximadamente 3.200 empregos diretos e 550 empregos na colheita (ASSOCIAÇÃO..., 2010).

Uma das preocupações e motivação da associação é disseminar informações técnicas, incentivar e conscientizar todos que compõem a rede da necessidade gerencial, mostrando a importância dessa prática para equilibrar a cadeia e evitar prejuízo geral e especulação. Essas práticas corroboram as da pesquisa de Bijman e Hendrikse (2003), pois os autores destacaram que o papel das cooperativas/associações é fazer a ligação do mercado com o produtor e, com isso, agir contras as ineficiências existentes na cadeia, de modo a reduzir a assimetria informacional para poder trabalhar com o desenvolvimento de novos produtos e novos conceitos de marketing. Essas práticas surgiram da necessidade e da tentativa de aumentar o poder de barganha frente aos compradores, que se beneficiam dos problemas que permeiam a cadeia de suprimentos. Além disso, devido às diferentes formas de comercialização da alface no mercado, os problemas se agravam com a sazonalidade.

$\mathrm{Na}$ tentativa de conscientizar os produtores da necessidade da gestão da propriedade, da necessidade de evitar os excessos produtivos e ampliar o mix de produtos, para evitar a monocultura, que acarreta em abusiva utilização de defensivos, a Aphortesp organiza e dissemina informações junto aos associados, evitando que o descontrole dessas variáveis interfira no custo de produção dos produtores e produtores parceiros. Além disso, incentivam a adesão e difusão da marca única, certificando a origem e procedência do produto. Essa marca fortalece a relação entre produtores e compradores, pois esses compradores associam a marca às boas práticas de gestão e plantio.

0 quadro 3 mostra um resumo dos pontos fracos e fortes dos produtores de alface sob o ponto de vista da Aphortesp. Embora a alface seja um produto com características produtivas específicas, a alta perecibilidade torna seu ciclo produtivo de alto risco. Adicionalmente, agregada à carência de gestão empresarial estratégica por parte de todos os 
Quadro 3. Pontes fortes e fracos da cadeia de suprimentos de alface segundo agentes associados.

\begin{tabular}{|c|c|}
\hline \multicolumn{2}{|r|}{ Alface } \\
\hline Pontos fortes & Pontos fracos \\
\hline $\begin{array}{l}\text { Safra durante todo o ano } \\
\text { Alto volume produzido } \\
\text { Ciclo produtivo curto }\end{array}$ & $\begin{array}{l}\text { Desequilíbrios entre oferta e demanda } \\
\text { Falta de gestão empresarial } \\
\text { Falta de gestão logística para minimizar os custos logísticos } \\
\text { Ainda há falta de flexibilidade em se tratando de certas variedades } \\
\text { Poucos produtores preocupados em melhorar e inovar o processo } \\
\text { Falta de um banco de dados para avaliar sazonalidade e históricos de preço } \\
0 \text { programa brasileiro de modernização da horticultura é por adesão voluntária. }\end{array}$ \\
\hline
\end{tabular}

Fonte: Elaborado pelos autores.

produtores, inclusive associados, a gestão da cadeia se torna um processo ainda mais complexo; amenizado somente pelas características físicas particulares do cultivar, que viabiliza a produção durante todo o ano.

No último nível, o de consumo, ocorre a transação entre varejista e consumidor e, em alguns casos, do produtor com o consumidor final. Nesse último caso, ainda há uma reduzida parcela de produtores que mantêm essa relação com os consumidores, ou seja, transações diretas. Casos como esses ocorrem somente quando o produtor exerce função de comercialização, podendo ser através de feiras livres ou atacadistas permissionários localizados no Ceagesp. Entretanto, os resultados da pesquisa indicam que as práticas de comercialização pelos produtores são realizadas somente para o caso de grandes produtores. Os pequenos e médios preferem dedicar-se exclusivamente à produção.

\subsection{Coordenação da cadeia de suprimentos}

Os atacadistas em geral são responsáveis pela comercialização de bens e/ou serviços para clientes que vão revendê-los, como por exemplos os supermercados. Há diversas categorias de atacadistas, de acordo com Rosenbloom (1999):

- Atacadistas especializados: trabalham com produtos específicos, como os entrepostos agrícolas;

- Atacadistas comerciais: que assumem a posse dos produtos, dos estoques, e transportam e negociam com o varejo;

- Agentes e comissionários: intermediários que não assumem a posse do produto, mas sim a negociação; e

- Escritório de venda dos produtores: locais fora das propriedades em que os produtores distribuem as mercadorias aos demais intermediários, sejam eles atacadistas tradicionais ou representantes e agentes comissionados.

Em São Paulo, um dos maiores centros de distribuição de produtos hortifrutigrangeiros Ceagesp - foi construído no final dos anos 1960, com o intuito de oferecer a esses produtores infraestrutura mínima para escoamento da produção agrícola.
Todavia, nas últimas décadas, diversos problemas afetaram esse sistema de comercialização. As entrevistas conduzidas com atacadistas da Ceagesp no período de julho a novembro de 2007 revelam que os principais gargalos são consequência de:

- Sistema logístico ineficiente: os produtos são manipulados diversas vezes, contribuindo para que a perda qualitativa seja mais rápida;

- A grande maioria dos produtos ainda é comercializada em caixas de madeira, sem padronização e manipuladas sem os devidos cuidados. Uma quantidade ínfima de produtos chegam aos atacadistas embalados e, com dados de origem;

- Quando as embalagens são plásticas, não se nota a preocupação de higienizá-las, fator esse que contribui para acentuar as perdas pós-colheita; e

- 0 sistema de comercialização exige vistoria individual e a grande maioria das vendas é feita por consignação no mercado, ou seja, pagamento caso haja venda.

Apesar de haver um Centro de Qualidade em Horticultura na Ceagesp (SECCQH), esse órgão desenvolve somente programas de apoio ao produtor para estimulá-lo no aprimoramento de técnicas agrícolas como: classificação, rotulagem e embalagens. Suporte esse estendido ao processo de comercialização, para ampliar a transparência nas negociações e definição dos preços praticados. Para o curto prazo, iniciativas podem prover o mercado de suas ineficiências. Contudo, como a adesão a esses programas é voluntária, os benefícios ainda não são percebidos e disseminados pela cadeia de suprimentos.

Por consequência, cada vez mais há um crescente interesse dos varejistas em atuar de maneira mais próxima dos produtores, mostrando omesmo comportamento já disseminado por grandes redes de varejo em países desenvolvidos, em especial a do Reino Unido (HUGHES; MERTON, 1996; FEARNE; HUGHES, 1999; HINGLEY, 2001; DOLAN; HUMPREY, 2000; CLEMENTS; LAZO; MARTIN, 2008). 0 setor de produtos frescos nas modernas e grandes redes varejistas é, atualmente, um importante condicionante estratégico. Garantir regularidade no fornecimento das lojas com produtos de alta qualidade é condicionante 
para a compra de outros produtos, já que a maioria dos consumidores desses produtos visitam as lojas três ou mais vezes durante a semana. Além disso, para algumas variedades, os preços podem exceder em até $130 \%$ os custos de produção em decorrência dos processos de embalagem, por exemplo (MAINVILLE; PETERSON, 2005).

Dada essa representatividade da seção de hortícolas para o varejo, através da compilação dos dados da pesquisa de campo expostos na Tabela 2 foi possível identificar alguns aspectos priorizados tanto pelos varejistas quanto pelos atacadistas. Com relação aos varejistas, a variável qualidade do produto e flexibilidade na entrega é a mais relevante para os três supermercados entrevistados. lsso é possivel através da utilização de contratos em que as cláusulas especificam características exigidas. Entretanto, os contratos formais são utilizados apenas por grandes redes de varejo, para os demais casos o contrato é informal ou inexistente. Esse resultado mostra que a coordenação da cadeia é feita quase que exclusivamente por meio de relações de confiança.

Todavia, diferentemente do varejo, para os atacadistas essa variável ainda não é relevante na manutenção e seleção dos fornecedores. Embora os atacadistas considerem que essas variáveis sejam importantes na seleção dos produtores e fornecedores, as relações são totalmente baseadas na confiança.

Outro ponto de divergência é em relação ao preço. Os varejistas o consideram importante critério para seleção de seus parceiros comerciais. Os atacadistas o avaliam como razoável, pois essa variável não interfere no modo como as transações e as relações são estabelecidas. Contudo, como não há nenhuma série histórica para comparação dos preços praticados, a avaliação desses resultados encontrados não pode ser generalizada. Entretanto, vale ressaltar que, diferentemente dos varejistas que negociam preço mensal para o produto, o atacadista é refém do equilíbrio entre oferta e demanda.

Através das entrevistas foi possível identificar problemas que comprometem a gestão da cadeia como um todo. Algumas mudanças envolvem investimentos e/ou melhorias estruturais na Ceagesp e outras na forma como a comercialização e distribuição dos

Tabela 2. Aspectos priorizados pelos atacadistas e varejistas.

\begin{tabular}{lll}
\hline \multicolumn{1}{c}{ Variáveis } & \multicolumn{1}{c}{ Atacado } & \multicolumn{1}{c}{ Supermercado } \\
\hline Qualidade & Importante & Muito importante \\
Preço & Moderado & Importante \\
Tempo de entrega & Importante & Importante \\
Confiabilidade da entrega & Importante & Importante \\
Flexibilidade & Importante & Muito importante \\
Capacidade de inovação & - & Importante \\
\hline
\end{tabular}

Fonte: Elaborado pelos autores. atacadistas que lá atuam são realizadas. É fundamental que todos os elos da cadeia se modernizem. Há indicações que mudanças simples no modo de gestão dos negócios de atacadistas e produtores reduziriam a inadimplência e de imediato evitariam prejuizos para ambos. Também precisam se conscientizar que oferecer produtos de qualidade é mais vantajoso que quantidade. Além disso, os atacadistas deveriam ser mais proativos na tentativa de modernizar a comercialização, incentivando seus fornecedores a participaram dos programas de capacitação promovidos pelo entreposto. Esse ponto auxiliaria a ampliar o conhecimento técnico e incentivaria o SECCQH a promover e desenvolver novas parcerias com órgãos de pesquisa e universidades.

A Tabela 3 fornece uma visão geral dos aspectos que dificultam as transações entre atacadistas e seus fornecedores (produtores). De acordo com as respostas obtidas para cada questão, foi feita uma média para obtermos um valor padrão de análise. 0 objetivo não era analisar os resultados por meio de tabulações estatísticas. A amostra não é probabilística, sendo o número de atacadistas entrevistados limitado. 0 objetivo dessas questões, para o estudo, é realizar uma análise qualitativa dessas variáveis, descrevê-las e compreender quais elementos podem contribuir para que haja melhorias na coordenação da cadeia.

De acordo com os entrevistados, avaliar a qualidade do produto, negociar com os fornecedores, mantê-los fiéis, garantir regularidade no fornecimento e garantir regularidade nas entregas são variáveis com nível razoável de dificuldade. A maioria dos atacadistas busca manter relacionamentos duradouros e de parceria com seus fornecedores. Embora tenham conhecimento das ações oportunistas que podem ocorrer pelo fato de não existirem contratos formais e nem informais percebeu-se, durante a pesquisa de campo, que há uma relação de confiança entre as partes. A grande

Tabela 3. Nível de dificuldade nas transações entre atacadistas e produtores.

\begin{tabular}{lc}
\hline \multicolumn{1}{c}{ Níveis de dificuldade } & Atacadista $\Leftrightarrow$ Produtor \\
\hline Regularidade no fornecimento & Moderado \\
Avaliar a qualidade do produto & Moderado \\
Avaliar a sanidade dos insumos & Difícil \\
Negociar com fornecedores & Moderado \\
Manter fornecedores fiéis & Moderado \\
Cumprir contratos & Indiferente \\
Garantir regularidade na entrega & Moderado \\
Prever volume de vendas & Difícil \\
Negociar com compradores & Moderado \\
Negociar preço na sazonalidade & Moderado \\
Negociar preços e fornecimento & Indiferente \\
quando há contratos informais & \\
\hline Fonte: Elaborado pelos autores. &
\end{tabular}


maioria dos atacadistas comercializam seus produtos na Ceagesp há mais de 20 anos e, desde então, negociando com os mesmos fornecedores. Para um dos entrevistados,

[...] a qualidade sempre será priorizada, até mesmo porque com melhores produtos você consegue preços mais atrativos; no entanto, quando seu fornecedor está com problemas na colheita e isso de certa forma interfere na qualidade do produto, você não deixa de comprar. 0 que mais valorizamos nessa relação é a confiança.

Para aqueles que classificaram como muito difícil o cumprimento do padrão das variáveis analisadas, é possível concluir que os indícios de alta rotatividade de fornecedores são agravados quando há divergências quanto à forma de pagamento, ocasionadas pela alta inadimplência e a não satisfação do preço pago ao produtor. Mesmo assim, as questões que se referem a cumprimento de contratos formais e dificuldades em negociar preços e fornecimento são consideradas sem importância. Esse dado mostra que os entrevistados não demonstram interesse em formalizar suas transações por meio de contratos mesmo quando há insatisfação de uma das partes ou de ambas. Quando há descontentamento de uma das partes devido a eventuais falhas no abastecimento, qualidade do produto e até mesmo preço, ambos acreditam não ser vantajoso trocar de fornecedor e/ ou comprador.

Segundo o próprio SECCQH, a precariedade e a falta de informação e de infraestrutura, aliadas às características de uma hortaliça considerada extremamente sensível e de difícil manuseio, tornam inevitáveis os efeitos exógenos. Nesse caso, prever o volume de vendas, assim como avaliar a sanidade dos insumos e dos alimentos foram as únicas variáveis que os atacadistas classificaram como de difícil mensuração.

\section{Considerações finais}

Os produtores precisam atender as necessidades de um mercado cada vez mais exigente, ter produtos com alta qualidade para conquistar os melhores compradores e obter preços mais competitivos. As estratégias de parceria passam a ser vistas como impulsionadoras da gestão da cadeia de suprimentos para esse tipo de alimento, pois viabilizam compras e, portanto, reduzem custos produtivos; além de incentivar a gestão logística para evitar transportar produtos com carga reduzida.

Dentro desse contexto, os supermercados adotaram a estratégia de diminuir os riscos inerentes às transações combinando diferentes tipos de governança.
Embora os preços da alface sejam definidos pelo mercado, os contratos (formas híbridas) permitem a transferência de grande parte dos riscos das transações aos fornecedores/produtores, através da fixação de preços e especificações requeridas para a aceitação do produto,. Dentro dessa lógica que visa à padronização do produto, algumas redes varejistas investem em sistemas de informação para facilitar a coordenação e gestão das transações envolvendo fornecedores e compradores. Essa prática torna-se eficaz principalmente quando o produto transacionado tem alta especificidade e é ofertado por vários agentes.

Mesmo assim, independente da estrutura de governança, para todas as transações analisadas percebeu-se forte tendência à construção de reputação junto a fornecedores, seja por meio de contratos formais de longo prazo ou predominância de relações de longo prazo baseados na confiança. Essa relação duradoura permite aos fornecedores (produtor, atacadista e varejista) adquirirem conhecimento das necessidades de cada comprador e, consequentemente, investir em capacitações que melhorem e contribuam não apenas para que haja agregação de valor ao produto, mas que também promovam a melhoria na gestão e coordenação da cadeia de suprimentos da alface.

Em suma, independente dos esforços dos agentes para estimular o desenvolvimento dessa cadeia de suprimentos, as evidências empíricas ressaltam um fato importante e de grande impacto na coordenação da cadeia, principalmente para pequenos e médios produtores: a relevância das atividades gerenciais. Embora os produtores busquem melhoria tecnológica e diferenciação dos produtos, todos estão expostos às variações externas que influenciam diretamente o mercado, dificultando, para a grande maioria, a reavaliação de seus processos gerenciais e, principalmente, dos fatores que comprometem a eficiência produtiva. Esse dado representa uma excelente oportunidade para futuras pesquisas que priorizem analisar o impacto da falta de gestão na coordenação da cadeia e como esses problemas podem ser atenuados para que haja uma redução do poder de barganha dos supermercados em relação aos outros integrantes da cadeia.

\section{Referências}

ASSOCIAÇÃO BRASILEIRA DE SUPERMERCADOS - ABRAS. Ranking 2007. Revista SuperHiper, v. 33, n. 375, maio 2007.

ASSOCIAÇÃO DOS PRODUTORES E DISTRIBUIDORES DE HORTI-FRUTI DO ESTADO DE SÃO PAULO - APHORTESP. 2010. Disponível em: <http:// www.aphortesp.com.br/aphortesp>. Acesso em: 03 dez.2010. 
BESANKO, D.; DRANOVE, D.; SHANLEY, M. Sustaining Competitive Advantage. In: BESANKO, D. et al. Economics of strategy. 2nd ed. New York: John Wiley \& Sons, 2000. p. 443-481.

BIJMAN, J.; HENDRIKSE, G. Co-operatives in chains: institutional restructuring in the Dutch fruit and vegetables industry. Journal on Chain and Network Science, v. 3, n. 2, p. 95-107, 2003. http://dx.doi. org/10.3920/JCNS2003.x033

BOTEON, M. Desafios horticultura nacional. Hortifruti Brasil, 2006. Disponivel em: <http://www.cepea.esalq. usp.br/pdf/apresentacao_hortitec_jun06.pdf>. Acesso em: 31 maio 2006.

BOWERSOX, D. J.; CLOSS, D. J. Logistical management: the integrated supply chain process. New York: McGrawHill., 2001.

CHOPRA, S.; MEINDL, P. Supply Chain Management. 4th ed. Upper Saddle River: Prentice Hall, 2009.

CLEMENTS, M. D.; LAZO, R. M.; MARTIN, S. K. Relationship connectors in NZ fresh Produce supply chains. British Food Journal, v. 110, n. 4-5, p. 346-360, 2008. http:// dx.doi.org/10.1108/00070700810868898

COMPANHIA DE ENTREPOSTOS E ARMAZÉNS GERAIS DE SÃO PAULO - CEAGESP. Institucional. Disponível em: <http://www.ceagesp.gov.br>. Acesso em: 29 out. 2010.

COMPANHIA DE ENTREPOSTOS E ARMAZÉNS GERAIS DE SÃO PAULO - CEAGESP. Transporte e logística de alimentos e flores. 2007. Disponível em: <http:// www.agroonline.com.br/agronoticias>. Acesso em: 05 jul. 2010.

COOPER, M. C.; LAMBERT, D. M.; PAGH, J. D. Supply chain management: more than a new name for logistics. The International Journal of Logistics Management, v. 8, n. 1, p. 1-13, 1997. http://dx.doi. org/10.1108/09574099710805556

DAVIS, J. H.; GOLDBERG, R. A. A concept of agribusiness. Boston: Harvard University, 1957. 136 p.

DOLAN, C.; HUMPREY, J. Governance and trade in fresh vegetables: the impact of UK supermarkets on the African horticulture industry. Journal of Development Studies, v. 37, n. 2, p. 147-176, 2000. http://dx.doi. org/10.1080/713600072

EISENHARDT, K. M. Building theories from case study research. Academy of Management Review, v. 14, n. 4, p. 532-550, 1989.

EMBRAPA. 2010. Disponivel em: <http://www.cnph. embrapa.br/paginas/hortalicasemnumeros>. Acesso em: 20 out. 2010.

FARINA, E. M. M. Q. Competitividade e Coordenação de Sistemas Agroindustriais. Gestão \&t Produção, v. 6, n. 3, p. 147-161, dez.1999. http://dx.doi.org/10.1590/S0104530X1999000300002

FEARNE, A.; HUGHES, D. Success factors in the fresh produce supply chain: insights from the UK. Supply Chain Management, v. 4, n. 3, p. 120-128, 1999. http://dx.doi. org/10.1108/13598549910279567

HINGLEY, M. Relationship Management in the supply chain. International Journal of Logistic Management, v. 12, n. 2, p. 57-71, 2001. http://dx.doi. org/10.1108/09574090110806299

HUGHES, D.; MERTON, I. Partnership in produce: the J Sainsbury approach to managing the fresh produce supply chain. Supply Chain Management, v. 1, n. 2, p. 4, 1996 http://dx.doi.org/10.1108/13598549610155251

INSTITUTO BRASILEIRO DE GEOGRAFIA E ESTATISTICA - IBGE. Pesquisa de Orçamento Familiar. IBGE, 2002-2003. Disponível em: <http://www.ibge.gov. br>. Acesso em: 08 out. 2010.

MACHADO, E.L. O papel da reputação na coordenação vertical da cadeia produtiva de frutas, legumes e verduras frescos. 2002. 182 f. Tese (Doutorado)-Faculdade de Economia, Administração e Contabilidade, Universidade de São Paulo, São Paulo, 2002.

MAINVILLE, D. Y.; PETERSON, C. H. Fresh produce procurement strategies in a constrained supply environment: case study of Companhia Brasileira de Distribuição. Review of Agricultural Economics, v. 27, n. 1, p. 130-138, 2005. http://dx.doi.org/10.1111/j.14679353.2005.00212.x

MANIKAS, 1.; TERRY, L. A. A case study assessment of the operational performance of a multiple fresh produce distribution centre in the UK. British Food Journal, v. 111, n. 5, p. 421-435, 2009. http://dx.doi. org/10.1108/00070700910957276

PEDROZO, E. Alface para todo dia. Revista Supervarejo, v. 8 , n. 84, p. 55, ago. 2007.

PÉNEAU, S. et al. Freshness of fruits and vegetables: consumer language and perception. British Food Journal, v. 111 , n. 3, p. 243-256, 2009. http://dx.doi. org/10.1108/00070700910941453

PENROSE, E. A economia da diversificação. Revista de Administração de Empresas, v. 19, n. 4, p. 7-30, 1959.

PEREZ, C.; CASTRO, R.; FURNOLS, M.F. The pork industry: a supply chain perspective. British Food Journal, v. 11 , n. 3, p. 257-274, 2009. http://dx.doi. org/10.1108/00070700910941462

PIGATTO, G.; ALCANTARA, R.L.C. Distribution channel relationship: a proposal of an analysis matrix". Gestão \& Produção, v. 14, n. 1, p. 155-167, 2007. http://dx.doi. org/10.1590/S0104-530X2007000100013

REARDON, T.; HENSON, S.; BERDEGUÉ, J. Proactive fasttracking diffusion of supermarkets in developing countries: implications for market institutions and trade. Journal of Economic Geography, v. 7, n. 4, p. 399-413, 2007. http://dx.doi.org/10.1093/jeg/lbm007

ROCHA, D. Câmara Setorial da cadeia produtiva de hortaliças: o desafio de representar um setor importante. 2007. Disponivel em: <http://www.ambienteemfoco.com.br>. Acesso em: 06 dez. 2007.

ROSENBLOOM, B. Marketing channels: a management view. 6nd ed. Orlando: Dryden Press, 1999.

SÃO PAULO (Estado). Secretaria de Agricultura e Abastecimento. Coordenadoria de Assistência Técnica Integral. Instituto de Economia Agrícola. Levantamento censitário de unidades de produção agrícola do Estado de São Paulo - LUPA 2007/2008. São Paulo: SAA/CATl/ IEA, 2008. Disponivel em: <http://www.cati.sp.gov.br/ projetolupa>. Acesso em: 15 out. 2010.

SCRAMIN, F. C. L.; BATALHA, M.O. Método para análise de benefícios em cadeias de suprimentos: um estudo de caso. Gestão \&t Produção, v. 11, n. 3, p. 331-342, set./ dez. 2004.

SILVA, C.A.B.; BATALHA, M.0. Competitividade em sistemas agroindustriais: metodologia e estudo de caso. In: WORKSHOP BRASILEIRO DE SISTEMAS 
AgrOAliMENTARES, 2., 1999, Ribeirão Preto. Anais... Ribeirão Preto: PENSA/FEA/USP, 1999. p. 9-20.

TAYLOR, D. H.; FEARNE, A. Towards a framework for improvement in the management of demand in agrifood supply chains. Supply Chain Management, v. 11, n. 5, p. 379-384, 2006. http://dx.doi. $\operatorname{org} / 10.1108 / 13598540610682381$

TAYLOR, D. H.; FEARNE, A. Demand management in fresh food value chains: a framework for analysis and improvement. Supply Chain Management, v. 14, n. 5, p. 379-392, 2009. http://dx.doi.org/10.1108/13598540910980297

VASCONCELOS, M. C. R. L.; MILAGRES, R.; NASCIMENTO, E. Strategy of relations among the members of the productive chain in Brazil: reflections on the theme. Gestão \&t Produção, v. 12, n. 3, p. 393-404, 2005.

VOSS, C.; TSIKRIKTSIS, N.; FROLICH, M. Case research in operations management. International Journal of Operations \& Production Management, v. 22, n. 2, p. 195-219, 2002. http://dx.doi. org/10.1108/01443570210414329

WILSON, N. The supply chains of perishable products in northern Europe. British Food Journal, v. 98, n. 6, p. 9-15, 1996. http://dx.doi.org/10.1108/00070709610131320

WOOD JUNIOR, T.; ZUFFO, P. K. Supply Chain Management. Revista de Administração de Empresas, v. 38, n. 3, p. 55-63, julho-setembro 1998.

YIN, R. K. Case study research: design and methods. 2nd ed. Beverly Hills: Sage Publications, 1994.

ZYLBERSTAJN, D. Estruturas de governança e coordenação do agribusiness: uma aplicação da nova economia institucional. 1995. 238 f. Tese (Livre Docência) - Faculdade de Economia, Administração e Contabilidade, Universidade de São Paulo, 1995.

\title{
Strategic management of relationships in lettuce supply chain
}

\begin{abstract}
Considering the current scenario, outlined by the technological changes, there is a necessity to reassess the organizational structures, specially the supply chain of perishable products, in order to achieve quality through a closer involvement between stakeholders and also to identify the main bottlenecks that hinder the coordination of the chain. The aim is to map and analyze the transactions along the lettuce supply chain to identify the challenges to be overcome by the producers to verify which the main bottlenecks to the coordination of this chain are. The choice of the lettuce chain occurred for its being a relatively complex chain. The various types of products transacted, the level of raw material processing and the institutional environment are some of the variables that make the coordination of this chain difficult, and it is regarded as one of the least developed in Brazil. In this context, producers associations gain importance and become an integral part of a strategic process aimed at a better coordination of the production chain.
\end{abstract}

\section{Keywords}

Supply chain. Management. Coordination. Lettuce. 